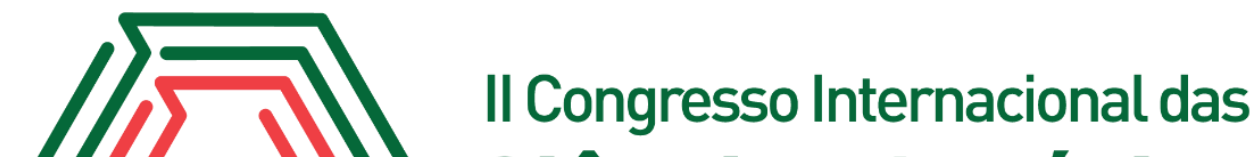 Ciências Agrárias COINTER - PDVAgro 2017
}

\section{DISPONIBILIDADE DE POTÁSSIO EM UM LATOSSOLO AMARELO SOBRE DIFERENTES SISTEMAS DE PRODUÇÃO}

\author{
Apresentação: Pôster
}

João Carlos dos Santos Duarte ${ }^{1}$; Daniela Samara Abreu das Chagas ${ }^{2}$; Fiama Kelly Melo Nunes $^{3}$; Gabriel Anderson Martins dos Santos ${ }^{4}$; Éder Silva de Oliveira ${ }^{5}$

\section{Introdução}

Dentre os elementos essenciais para o desenvolvimentos das plantas, o $\mathrm{K}$ tem seu destaque por ser um macronutriente, ou seja, ele é requerido em grandes quantidades pelo vegetal por fazer parte de processos vitais para a planta. Segundo Meurer (2006) o cátion mais abundante na planta é o K, tendo sua importância no estado energético do vegetal, na translocação e no armazenamento do carboidrato produzido na fotossíntese além da regulação osmótica nas células da planta.

Na solução do solo o K encontra-se disponível para as plantas na sua forma iônica livre $\left(\mathrm{k}^{+}\right)$ ou adsorvidos nas argilas (não disponível). Para que a planta possa absorver o K é necessário que o nutriente esteja o mais próximo possível da zona radicular, Barber (1995) apud Meurer diz que o principal mecanismo de transporte de $\mathrm{K}^{+}$livre da solução do solo até a zona de absorção ocorre por fluxo de massa e/ou difusão.

Os solos da Amazônia são podres em cátions básicos ( $\mathrm{Ca}, \mathrm{Mg}$ e $\mathrm{K})$, mas esses nutrientes podem ser retornáveis e ciclados dentro da própria floresta (LUIZÃO, 2007) com o auxilio da decomposição de liteiras e a própria movimentação de aerossóis (ARTAXO, 2006; PAULIQUEVIS, 2007).

A partir disso, esse trabalho tem por hipótese saber os níveis de $\mathrm{K}$ presente no solo são suficientes para nutrir dois sistemas de produção: pastagem e cultivo agrícola (açaí e milho) e em qual profundidade no perfil do solo esse nutriente estará em maior quantidade.

\footnotetext{
${ }^{1}$ Agronomia, Universidade Federal Rural da Amazônia, duarte.joaocarlos17@gmail.com

${ }^{2}$ Engenharia Florestal, Universidade Federal Rural da Amazônia, dsamaraabreu@hotmail.com

${ }^{3}$ Engenharia Florestal, Universidade Federal Rural da Amazônia, fiamamelo10@outlook.coml

${ }^{4}$ Agronomia, Universidade Federal Rural da Amazônia, gabirmartins20@gmail.com

${ }^{5}$ Professor Mestre, Universidade do Estado do Pará, ederso@uepa.br
} 


\section{Fundamentação Teórica}

A produção de forragem normalmente esta associada aos teores de potássio trocável no solo (MACEDO, 2013). O nível crítico de potássio no solo, para orientar o estabelecimento de pastagens em solos da região do Cerrado, tem sido estimado entre $50 \mathrm{mg} / \mathrm{dm} 3(0,13 \mathrm{cmolc} / \mathrm{dm})$ a $60 \mathrm{mg} / \mathrm{dm} 3$ (0,15 cmolc/dm) (VILELA et al., 2007c).

A adubação potássica ganha mais relevância ainda para a cultura do milho em virtude da elevada exigência de potássio da planta, sendo o segundo nutriente mais absorvido por ela, atrás apenas do nitrogênio. (COELHO \& FRANÇA, 1995). No Pará, sugere-se no máximo 60 kg ha-1 de K2O para produção entre 3 e 6 t ha-1 (CRAVO et al., 2007).

O açaizeiro (Euterpe oleracea Mart.) é uma espécie frutífera e produtora de palmito, nativa da Amazônia e tem como centro de origem o Estado do Pará, onde estão estabelecidas densas e diversificadas populações naturais (OLIVEIRA et al., 2007). A maioria do cultivo do açaizeiro paraense está implantada em solos de baixa fertilidade natural e com alto teor de alumínio trocável, exigindo o emprego de corretivos e fertilizantes para uma produtividade sustentada (GONÇALVES \& MEURER, 2010).

\section{Metodologia}

A área de estudo foi a fazenda Bela Vista a qual se localiza na latitude $1^{\circ} 54^{\prime} 30,64$ " S e longitude $48^{\circ} 53^{\prime}$ 18,54” O, situada no município de Abaetetuba no estado do Pará. Predominam no município o Latossolo Amarelo distrófico, textura média, associado ao Podzol Hidromórfico e Solos Concrecionários Lateríticos Indiscriminados distróficos, textura indiscriminada, em relevo plano ( IDESP, 1977). O clima no município de Abaetetuba é do tipo Am, segundo a classificação de Köppen, que corresponde à categoria de super úmido. Apresenta altas temperaturas, inexpressiva amplitude térmica, e precipitações ambulantes.

A fazenda possui uma área de 500ha, sendo divida em área de pastagem, plantio de açaí, plantio de milho e APP. Mas, para o estudo só foram utilizadas as áreas de pastagem, plantio de açaí e milho. Foi realizada uma coleta de solo no primeiro e no terceiro final de semana do mês de maio do ano em curso, na profundidade de $0-20 \mathrm{~cm}$ e $20-40 \mathrm{~cm}$ para quantificar a disponibilidade de $\mathrm{k}^{+}$a essas cultura. Foram utilizados 6 tratamentos com 4 repetições cada: T1 - Pastagem na profundidade 0-20cm; T2 - Pastagem na profundidade 20-40cm; T3 - Açaí na profundidade 0-20cm; T4 - Açaí na profundidade 20-40cm; T5 - Milho na profundidade 0-20cm; T6 - Milho na 
profundidade $20-40 \mathrm{~cm}$. Após a coleta do material o mesmo foi armazenado em sacos plásticos, identificados e levados ao laboratório. No laboratório o solo foi posto para secar e depois peneirado, a determinação de K no solo é feita por extração pela solução de MEHLICH 1.

A concentração de $\mathrm{K}$ presente na mostra é dada pela seguinte expressão.

$$
\text { cmolc de } \frac{K^{+}}{d m^{3}} \operatorname{de} T F S A=\frac{(L a-b)}{a}
$$

Em que $\boldsymbol{L} \boldsymbol{a}$ é a leitura da amostra no aparelho, $\boldsymbol{a}$ e $\boldsymbol{b}$ são os coeficientes angular e linear da reta.

Para a obtenção dos dados estatísticos foi utilizado o software AGROSTAT 1.1.0.702, no qual os dados foram processados e submetidos ao teste de Tukey a 5\% de probabilidade, para comparar as médias e obter a correlação entre as variáveis mencionadas. Também foi utilizado o programa computacional ArcGIS 10.5.1, no laboratório de geoprocessamento da Universidade Estadual do Pará - UEPA, para elaboração de um mapa em que mostra a disponibilidade de $\mathrm{K}$ na área da fazenda.

\section{Resultados e Discussões}

Os resultados obtidos para a disponibilidade de $\mathrm{K}$ apontam que não houve significância a 5\% de probabilidade pelo teste de Tukey, conforme demonstra a tabela 1.

Tabela 1: Análise de variância para disponibilidade de K . Fonte: Própria

\begin{tabular}{lcccc}
\hline FV & GL & SQ & QM & F \\
\hline Tratamentos & 5 & 0.03971 & 0.00794 & $2.0371 \mathrm{~ns}$ \\
Resíduo & 18 & 0.07017 & 0.00390 & \\
\multicolumn{7}{l}{ Total } & & & \\
\hline ** significativo ao nível de $1 \%$ de probabilidade $(\mathrm{p}<.01) ; *$ significativo ao nível de 5\% de probabilidade $\quad(.01=<\mathrm{p}<$ \\
.05) ns não significativo $(\mathrm{p}>=.05)$.
\end{tabular}

Observa-se que a disponibilidade de K no solo em estudo e não depende da profundidade, ou seja, o nutriente pode estar tanto na camada de $0-20 \mathrm{~cm}$ quanto na camada de $20-40 \mathrm{~cm}$.

A disponibilidade de K no solo deve ser o suficiente para atender as necessidades da cultura, 
para o milho no Estado do Pará Cravo et al (2007) sugere uma quantidade máxima em torno $60 \mathrm{~kg}$ $\mathrm{ha}^{-1}$ de $\mathrm{K} 2 \mathrm{O}$ para produção entre 3 e $6 \mathrm{t} \mathrm{ha}^{-1}$. O K também irá influenciar na formação de uma boa pastagem Andrade et al (2014) diz que nos solos mais pobres, as doses recomendadas variam de 20 $\mathrm{kg} \mathrm{ha}^{-1}$ a $60 \mathrm{~kg} \mathrm{ha}^{-1}$ de $\mathrm{K}_{2} \mathrm{O}$, dependendo do teor de $\mathrm{K}$ disponível no solo e do tipo de pasto que se pretende formar. $\mathrm{O}$ açaí por ser uma cultura perene demande de quantidades consideráveis de $\mathrm{K}$ para que seus frutos sejam de melhor qualidade, devido o $\mathrm{K}$ atuar diretamente na formação dos frutos.

Figura 1: Distribuição dos teores de K na profundidade de $0-20 \mathrm{~cm}$ e $20-40 \mathrm{~cm}$, respectivamente, na Fazenda Bela Vista. Fonte: Própria
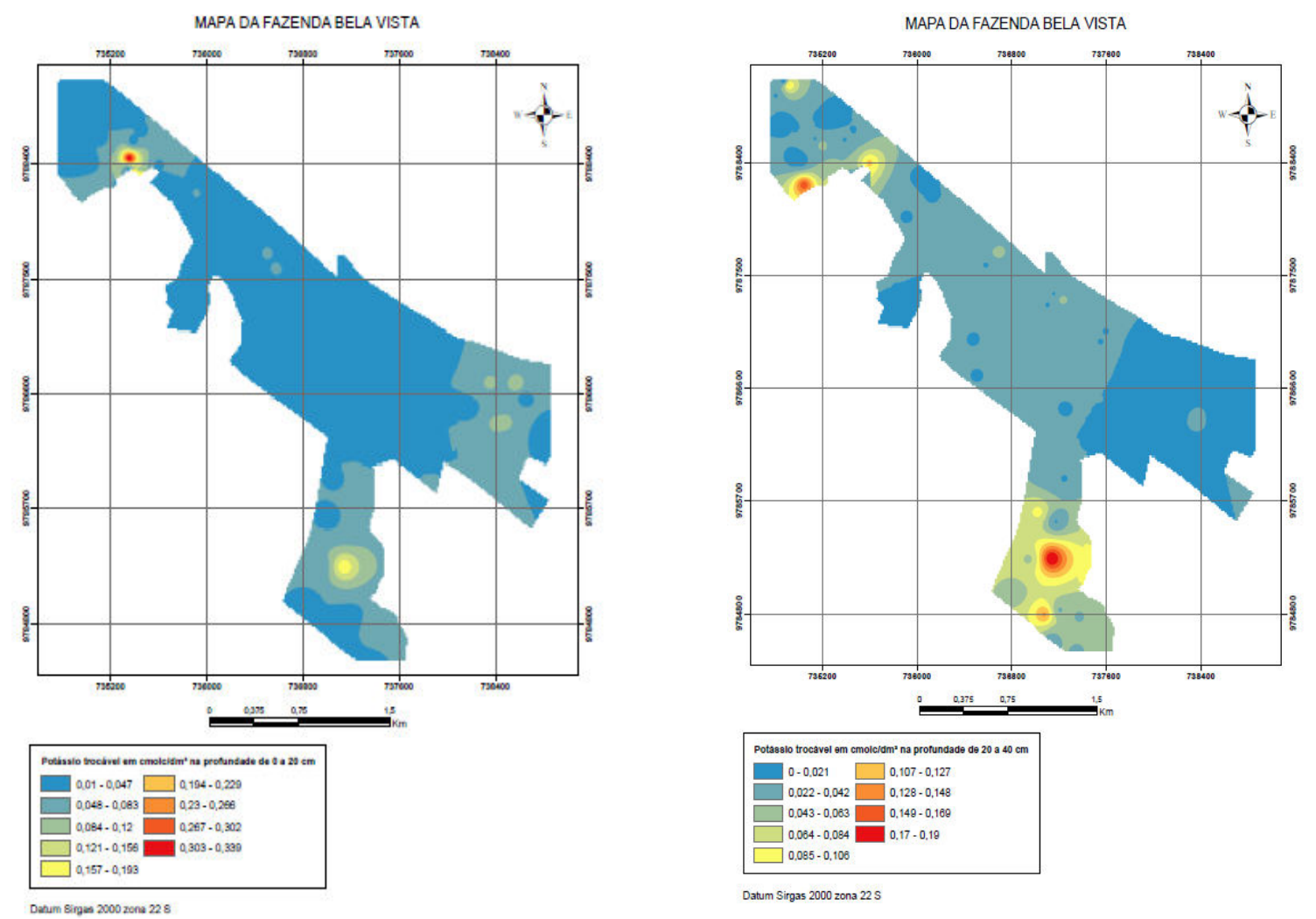

A figura 1 mostra a distribuição de $K$ disponível na área na profundidade de $0-20 \mathrm{~cm}$ e 20 - $40 \mathrm{~cm}$, a o predomínio da cor azul, indicando baixos níveis de $\mathrm{K}$ nessa área, evidenciando o que Luizão (2007) falou sobre os solos da região amazônica serem pobres em nutrientes bases. Como isso, tem-se que ser feita uma adubação potássica para que o solo possa disponibilizar esse nutriente para o pasto, milho e açaí, a partir disso a produtividade da fazenda irá aumentar. 


\section{Referências}

ANDRADE, C. M. S. D.; WADT, P. G. S.; ZANINETTI, R. A.; VALENTIM, J. F. Recomendação de Calagem e Adubação para Pastagens no Acre. Circular técnico: Embrapa. Rio Branco, Ac. 2014.

Artaxo, P. Oliveira, P. H. Lara, L. L. Pauliquevis, T. M. Rizzo, L. V. Pires, C. Paixão, M.A. Longo, K.M.Freitas, S. Correia , A. L. Efeitos climáticos de partículas de aerossóis biogênicos e emitidos em queimadas na Amazônia, Rev. Bras. Meteorologia, 21(3), 168-189, 2006.

BARBER, S. Mecanismo de absorção potássio pelas plantas. In: YAMADA et al., Eds. POTÁSSIO NA AGRICULTURA BRASILEIRA, Piracicaba, 1982.

COELHO, A.M.; FRANÇA, G.E. Seja o doutor do seu milho: nutrição e adubação. Informações Agronômicas, n.71, p.61- 67, 1995. (Encarte Técnico)

CRAVO, M.S.; SILVEIRA FILHO, A.; RODRIGUES, J.E.L.; VELOSO, C.A.C. Milho. In: CRAVO, M.S.; VIÉGAS, I.J.M.; BRASIL, E.C. Recomendações de adubação e calagem para o Estado do Pará. Belém: Embrapa Amazônia Oriental, 2007. p.153-155.

GONÇALVES, G. K.; MEURER, E. J. Alterações nas concentrações de fósforo em solos cultivados com arroz irrigado no Rio Grande do Sul. Revista Brasileira de Ciência do Solo, Porto Alegre, MG, v. 34, p. 465-471. 2010.

IDESP. 1977. Diagnóstico do Município de Abaetetuba. Belém: IDESP

Luizão, F. J. Ciclos de Nutrientes na Amazônia: Respostas às mudanças ambientais e climáticas. Cienc. Cult. vol.59 no.3 São Paulo July/Sept, 2007.

MEURER, E. J. Nutrição mineral de plantas. SBCS, Viçosa, 2006.

MACEDO, V. C. Adubação de implantação, manutenção e recuperação de capim-mombaça. Trabalho de conclusão do curso de graduação em Zootecnia da Universidade Federal de Goiás. Goiás, 2013.

OLIVEIRA, M. S. P.; FARIAS NETO, J. T.; PENA, R. S. Açaí: técnicas de cultivo e processamento. Fortaleza: Instituto Frutal, p.104. 2007. 